\title{
Pattern of Wound Complications and Postoperative Pain in Sublay versus Onlay Mesh Repair for Ventral Hernia
}

\author{
Aly Saber ${ }^{1, *}$, Adel R. Al-Masry ${ }^{2}$ \\ ${ }^{1}$ Port-Fouad General Hospital, Department of General Surgery, Port-Fouad, Port-Said, Egypt \\ ${ }^{2}$ Al-Mahalla Al-Koubra General Hospital, Al-Mahalla Al-Koubra, Egypt. \\ Email address: \\ Alysaber54@gmail.com (A. Saber), adelrm2003@yahoo.com (A. R. Al-Masry)
}

\section{To cite this article:}

Aly Saber, Adel R. Al-Masry. Pattern of Wound Complications and Postoperative Pain in Sublay versus Onlay Mesh Repair for Ventral Hernia. Journal of Surgery. Special Issue: Abdominal Surgery: Toward the Best. Vol. 4, No. 1-1, 2016, pp. 19-23.

doi: $10.11648 /$ j.js.s.2016040101.15

\begin{abstract}
Introduction: Apart from recurrence after ventral hernia repairs, other postoperative complications like seroma formation, hematoma, cellulitis, wound infection attributed largely to extensive dissection and tissue handling. Sublay technique has several advantages such as low rate of infection from subcutaneous tissues down to the mesh as it lies quite deep in the preperitoneal plane. Moreover the mesh implanted in the preperitoneal space unites and consolidates the anterior abdominal wall and also adheres to the posterior rectus sheath and renders it inextensible allowing no further herniation. The authors in this study tried to compare the pattern of wound complications and postoperative pain in sublay and onlay mesh repair for ventral hernia. Patients and Methods: A total of 200 patients with ventral hernias were enrolled and divided into main two groups; A and B. Group A patients were subjected to onlay mesh repair and Group B patients were subjected to sublay mesh repair. Operations were performed in Port-Fouad general hospital, Port-Fouad, Port-Said, Egypt and in the AlMahalla Al-Koubra general hospital, Al-Mahalla Al-Koubra, Egypt. End Points: The end points were of wound infection, mesh rejection and chronic postoperative pain. Results: There was no statistical difference between both groups regarding their demographic data such as age, sex, special habits and body mass index and co-morbidities. Patterns of mesh related wound complications as well as chronic postoperative pain were higher in onlay versus sublay repair with no statistical significance. Conclusion: sublay preperitoneal repair is a safe and an effective technique for ventral hernia surgery. Pattern of wound complications as postoperative wound infection, mesh removal and chronic pain are much less than when compared with the onlay maneuver.
\end{abstract}

Keywords: Ventral Hernia, Onlay, Sublay, Wound Complications

\section{Introduction}

Ventral hernia repairs are among the most common surgical operations performed worldwide and the incidence of post-operative wound-related complications due to mesh repair aimed at continuing research into the optimal method of treatment of these hernias [1]. Apart from recurrence other postoperative complications like seroma formation, hematoma, cellulitis, wound infection attributed largely to extensive dissection and tissue handling during hernia repair [2]. Factors affecting the status of surgical wound after hernia repair with mesh are, diabetes, corticosteroids use, smoking, advanced age; obstructive airways diseases $[3,4]$.

The most common method of mesh hernioplasty is the onlay technique [5]. Multiple defects are highly likely to be detected because of the wide undermining done and the weakest point of the repair that is most prone to recurrence is the mesh-tissue interface $[5,6]$. Sublay technique has several advantages such as low rate of infection from subcutaneous tissues down to the mesh as it lies quite deep in the preperitoneal plane [7]. Moreover the mesh implanted in the preperitoneal space unites and consolidates the anterior abdominal wall and also adheres to the posterior rectus sheath and renders it inextensible allowing no further herniation [8]. The authors in this study tried to compare the pattern of wound complications and postoperative pain in sublay and onlay mesh repair for ventral hernia. 


\section{Patients and Methods}

\subsection{Patients}

A total of 200 patients with paraumbilical, epigastric and incisional hernias were enrolled to the present study with the period from April 2003 to November 2011. Patients were divided into main two groups; A and B. Group A patients were subjected to onlay mesh repair and Group B patients were subjected to sublay mesh repair. The age of Group A patients ranged between 32 and 65 years with the mean as $48.5 \pm 9.95$ while in group B was $49.2 \pm 10$. Patients presented with strangulation or with corticosteroid therapy were excluded from the study. Operations were performed in Port-Fouad general hospital, Port-Fouad, Port-Said, Egypt and in Al-Mahalla Al-Koubra general hospital, Al-Mahalla Al-Koubra, Egypt.

Written consents were obtained from all patients before the study. The steps of both operative interferences were explained to all patients. The local ethics committee had approved all operative procedures. Ethical approval for this study was granted by the ethical review committee under supervision of the general director of Port- Fouad general hospital, Port-Fouad, Port-Said, Egypt.

\subsection{Randomization}

Randomization was performed prior to study commencement as follows: Opaque envelopes were numbered sequentially from 1 to 200 . A computer-generated table of random numbers was used for group assignment; if the last digit of the random number was from 0 to 4 , assignment was to Group A (onlay mesh repair), and if the last digit was from 5 to 9 , assignment was to Group B (sublay mesh repair). The assignments were then placed into the opaque envelopes and the envelopes sealed. As eligible participants were entered into the trial, these envelopes were opened in sequential order to give each patient his or her random group assignment. The envelopes were opened by the operating surgeon after patient consent and just prior to the surgery.

\subsection{End Points}

The end points were of wound infection, mesh rejection and chronic postoperative pain. Regarding the postoperative pain, we considered the Visual Analog Scale pain score, prosthesis awareness and return to normal physical activity. Chronic pain was defined as pain lasting more than three months [9]. Here we relied upon the already adopted a simplified scoring system for method of pain assessment that was advocated by our team in previous published data using the visual analog scale (VAS) and prosthesis awareness $[9,10]$.

\subsection{Statistical Analysis}

The statistical tests were run on a compatible personal computer using the Statistical Package for Social Scientists ( SPSS ) for windows 15. The values were expressed as means \pm standard errors of deviation. The mean values of the groups were compared by one-way analysis of variance (ANOVA ) and paired comparisons of the groups were done using the paired student $\mathrm{t}$ test. $\mathrm{P}<0.05$ was considered significant.

\subsection{Operative Technique}

\subsubsection{Onlay Mesh Repair}

The onlay repair was done under general anaesthesia with skin incision over the bulge or the defect. Using blunt dissection, both the rectus sheath and the defect containing the hernia contents were identified. The hernia sac was clearly dissected and the contents were removed and the margins of the defect were held by Kocher forceps. The sac was dealt with and its contents were reduced into the abdominal cavity. With non-absorbable suture, the defect in the linea alba was closed and a proline mesh of adequate size was placed on the rectus sheath and fixed with stitches. Hemostasis was secured and wound was closed over a suction drain. A dose of broad-spectrum antibiotic was given prior to anaesthesia [1].

\subsubsection{Sublay Mesh Repair}

The principles of the preperitoneal or sublay mesh repair included two main steps; mesh placement deep to the recti muscles and mesh extension well beyond the hernia defect. After the sac was being dissected and delineated, the defect is opened and the preperitoneal plane is created between the posterior rectus sheath and the rectus muscle for the placement of the mesh. The posterior rectus sheath along with the peritoneum is closed with zero prolene sutures. A prolene mesh tailored to the size is placed in the already created plane behind the recti. The mesh is secured with few interrupted $2 / 0$ polypropylene sutures. A suction drain is placed over the mesh. The anterior rectus sheath is closed with continuous $1 / 0$ polypropylene sutures. Another drain is placed in the subcutaneous plane and the skin closed. Drains were removed when drainage was less than $20 \mathrm{ml}$ in 24 hours. All the patients were given $1 \mathrm{gm} 3 \mathrm{rd}$ generation cephalosporin antibiotic preoperatively at the time of induction and continued till the 5th postoperative day twice daily. The hospital stay of the patients was also recorded down [1].

\section{Results}

There was no statistical difference between both groups regarding their demographic data such as age, sex, special habits and body mass index [ BMI ] and co-morbidities as shown in table 1. Regarding the clinical presentation of the ventral hernias in our patients, we observed that paraumbilical hernia was $40 \%$ and $42 \%$ of cases in group A and B respectively while epigastric hernia alone was $21 \%$ and $20 \%$ in group A and B respectively. Concomitant paraumbilical and epigastric hernias were $19 \%$ and $17 \%$ in group $\mathrm{A}$ and $\mathrm{B}$ respectively. Incisional hernia was observed in $20 \%$ and $21 \%$ in group A and B respectively as shown in table 2. 
Table 1. Showing subdivision of both groups regarding age and body mass index.

\begin{tabular}{|c|c|c|c|c|}
\hline & & GroupA & GroupB & Pvalue \\
\hline \multirow{2}{*}{ Age } & Age $<50\{32-----49\}$ & $\mathrm{N}=58$ & $\mathrm{~N}=56$ & \multirow{2}{*}{$\mathrm{P} \geq 0.05$} \\
\hline & Age $>50\{50-----65\}$ & $\mathrm{N}=42$ & $\mathrm{~N}=44$ & \\
\hline \multirow{3}{*}{ Sex } & Male & $N=42$ & $\mathrm{~N}=45$ & \multirow{3}{*}{$\mathrm{P} \geq 0.05$} \\
\hline & Female & $\mathrm{N}=58$ & $\mathrm{~N}=55$ & \\
\hline & $\mathrm{BMI}<25\{22---24.9\}$ & $\mathrm{N}=26$ & $\mathrm{~N}=22$ & \\
\hline \multirow[t]{3}{*}{ BMI } & $\mathrm{BMI}<30\{25---29.9\}$ & $\mathrm{N}=44$ & $\mathrm{~N}=50$ & \multirow[t]{3}{*}{$\mathrm{P} \geq 0.05$} \\
\hline & $\mathrm{BMI}>30\{30---34.9\}$ & $\mathrm{N}=30$ & $\mathrm{~N}=28$ & \\
\hline & Diabetes & $\mathrm{N}=31$ & $\mathrm{~N}=34$ & \\
\hline \multirow[t]{2}{*}{ Co-morbidity } & COPD & $\mathrm{N}=13$ & $\mathrm{~N}=10$ & \multirow[t]{2}{*}{$\mathrm{P} \geq 0.05$} \\
\hline & IHD & $\mathrm{N}=18$ & $\mathrm{~N}=20$ & \\
\hline
\end{tabular}

Table 2. Showing clinical presentations of ventral hernias in both groups.

\begin{tabular}{|c|c|c|c|c|c|}
\hline Presentation & GroupA & & GroupB & & Pvalue \\
\hline \multirow{2}{*}{ Paraumbilical (PU) hernia } & Male & 13 & Male & 14 & \\
\hline & Female & 27 & Female & 28 & \\
\hline \multirow{2}{*}{ Epigastric hernia } & Male & 12 & Male & 13 & \\
\hline & Female & 9 & Female & 7 & \\
\hline \multirow{2}{*}{ PU\& and epigastric hernias } & Male & 9 & Male & 8 & $\mathrm{P} \geq 0.05$ \\
\hline & Female & 10 & Female & 9 & \\
\hline \multirow{2}{*}{ Incisional hernia } & Male & 8 & Male & 9 & \\
\hline & Female & 12 & Female & 12 & \\
\hline Total & 100 & & 100 & & \\
\hline
\end{tabular}

The authors traced two levels of wound infection in this study with overall incidence rate as $8 \%$ and $23 \%$ for group A and $\mathrm{B}$ respectively. Superficial wound infection was observed in 5/ 100 patients $(5 \%)$ in group $A$ and in $9 / 100$ patients $(9 \%)$ in group B. two patients with mild deep wound infection occurred in group A and 6 cases of deep wound infection around the mesh were seen in group B; three were managed conservatively and the other three necessitated removal of the mesh. Sinus formation was observed in 1/100 patients in group $A$ and $5 / 100$ patients in group B representing $1 \%$ and $5 \%$ in group $\mathrm{A}$ and $\mathrm{B}$ respectively as shown in table 3 and graph 1.

Table 3. Showing pattern of mesh related wound complications in both groups.

\begin{tabular}{llll}
\hline Wound & GroupA & GroupB & Pvalue \\
\hline Superficial & 5 & 9 & \\
Deep & 2 & 6 & \\
Mesh rejection & 0 & 3 & $\mathrm{P} \geq 0.05$ \\
Sinus formation & 1 & 5 & \\
Overall & 8 & 23 & \\
\hline
\end{tabular}

As regard chronic postoperative pain due to mesh implant, no severe pain score according to VAS and only mild and moderate score were reported. In group A only mild pain was detected in 8 patients $(8 \%)$ with mean value and standard deviation as $2 \pm 1$ and 2 patients with moderate pain score $(2 \%)$ with mean value and standard deviation as $5.5 \pm 0.7$. In group B only mild pain was detected in 22 patients $(22 \%)$ with mean value and standard deviation as $3 \pm 0.97$ and 8 patients with moderate pain score $(8 \%)$ with mean value and standard deviation as $5.62 \pm 0.74$.

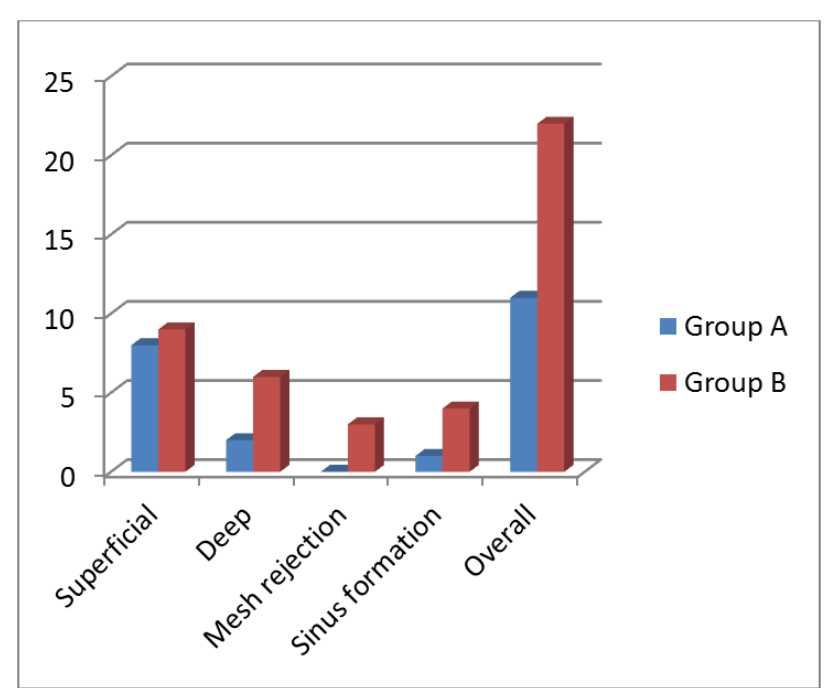

Graph 1. Showing pattern of mesh related wound complications in both groups

\section{Discussion}

The techniques of placement of mesh in ventral hernia repair include onlay and sublay techniques and some researchers described preperitoneal sublay technique as the gold standard for abdominal wall hernia repair [3,11 ]. Onlay mesh repair has the potential advantage of keeping the mesh separated from the abdominal contents by full abdominal muscle fascial wall thickness. The disadvantages of this repair include repair under tension, large subcutaneous dissection and wide undermining of tissues that allows for seroma formation, and mesh infection when the surgical wound becomes infected [12-14]. The main issue in case of 
onlay technique is increased risk for infection with postoperative complications such as seroma formation, hematoma, cellulitis, and wound infection have been attributed largely to the extensive dissection and tissue handling during hernia repair and greater intraoperative blood loss and these factors have been reported to be associated with increased wound infection [15].

The incidence of overall wound infection rates from onlay hernioplasty in previous published works was $25 \%$ to $40 \%$ $[13,16]$. Our data came in agreement with those published data regarding the superficial wound infections in onlay repair. Otherwise, deep wound and mesh infections was another item of our study. We reported $6 \%$ and 3\% for deep wound and mesh infections in onlay technique and these figures are comparable with other published data which confirmed that $10 \%$ of mesh repair patients were scored as having deep infection, for mesh infection was $6.7 \%$ and one third of these meshes had to be removed [17-19].

The main advantages of preperitoneal sublay mesh repair are fewer incidences of mesh infection and minimal morbidity $[16,20]$. The superficial wound infection rate was previously reports as 3-8 \% in sublay groups [3, 21]. While Stoppa reported a higher incidence in the early times of this maneuver up to $12 \%$ [22]. In agreement with those data, the authors in this study reported comparable rate of infection in their sublay repair patients. The explanation of this reduced incidence of infection in sublay than in onlay technique that the former has several advantages, one of which being not transmitting the infection from subcutaneous tissues down to the mesh, as it lies quite deep in the preperitoneal plane $[15,16,23,24]$. Also, Milad and his colleagues reported that the retromuscular plane is highly vascular and helps preventing infection, and if any infection occurs in the subcutaneous plane, it will not affect the mesh, as the mesh is retromuscular in a deeper plane [1,25].

The concern of chronic pain has also been raised in previous studies that reported $11 \%$ of patients had moderate to severe pain at 12 months after hernia repair [26]. Here in the present study, the authors reported a higher value of VAS score in onlay versus sublay repair with statistical significant difference. In a symposium on incisional hernia repair, some researchers argued that mesh can limit range of motion and result in a stiff abdomen [27]. Decreased abdominal wall compliance has been confirmed with threedimensional stereography [28]. Given the potentially negative long-term effects of prosthetic mesh repair, data characterizing the quality-of-life, chronic pain, and physical limitations of mesh implants should prove to be helpful [26] Regarding postoperative pain in previous studies, the mean VAS score was not statistically different compared with sublay versus onlay repair during rest and during activity [29-31].

\section{Conclusion}

The sublay preperitoneal repair with mesh is a safe and an effective technique for ventral hernia surgery. Pattern of wound complications as postoperative wound infection, mesh removal and chronic pain are much less than when compared with the onlay maneuver.

\section{References}

[1] Saber A, Bayumi EK. Onlay versus Sublay Mesh Repair for Ventral Hernia, Journal of Surgery. Special Issue: Abdominal Surgery: Toward the Best. 2016, 4(1-1): 1-4.

[2] R Godara, P Garg, H Raj, S Singla. Comparative Evaluation Of "Sublay" Versus "Onlay" Meshplasty In Ventral Hernias. The Internet Journal of Surgery. 2005,8 (1).

[3] Jat MA, Memon MR, Rind GH. SQA Shah. Comparative evaluation of "Sublay" versus "Inlay" meshplasty in incisional and ventral hernias. Pak J Surg 2011; 27(1):54-58S

[4] Chumpelick V, Klinge U, Rosch R, Junge K. Light weight meshes in incisional hernia repair. J of minimal Acces Surgery. Sept:2006, 2 : 117-23.

[5] Rana KV, Singh G, Deshpande NA, Bharathan VK, Sridharan S. Postoperative complications of mesh hernioplasty for incisional hernia repair and factors affecting the occurrence of complications. Med J DY Patil Univ 2013;6:25-31

[6] Shell DH, de la TorreJ, Andrades P,Vasconez LO. Open repair of ventral incisional hernias. Surg Clin North Am 2008;81:6183.

[7] Bhat Mahabhaleshwar G ,somasundaram santoshK. Preperitoneal Mesh Repair of incisional Hernia: A seven year retrospective study. Ind J Surg. 2007; 69: 95-8.

[8] Hameed F , Ahmed B, Ahmed A, Dab RH, Dilawaiz. Incisional Hernia Repair by Preperitoneal (Sublay) Mesh Implantation. A P M C, 2009;3 (1): January-June 27-31

[9] Aly Saber, Goda M Ellabban, Mohammad A Gad and Karam Elsayem. Open preperitoneal versus anterior approach for recurrent inguinal hernia: a randomized study. BMC Surgery 2012, 12:22 doi:10.1186/1471-2482-12-22

[10] Heba M. Mohamady, Asmaa A. Saber, Aly Saber. Effect of Interferential Therapy on Chronic Pain after Inguinal Hernioplasty. Journal of Surgery. Special Issue: Postoperative Pain Syndrome. 2015; 3(2-1): 14-17. doi: 10.11648/j.js.s.2015030201.13

[11] Parra JA, Revuelta S, Gallego T, Bueno J. et al. Prosthetic mesh used for inguinal \& ventral hernia repair : normal appearance \& complications in ultrasound \& CT. British Journalof Radiology 2004; 77: 261-265.

[12] Ibrahim AH, El-Gammal AS, Mohamed Heikal MM. Comparative study between 'onlay' and 'sublay' hernioplasty in the treatment of uncomplicated ventral hernia. Menoufia Med J 2015;28:11-6

[13] Chien JS, Tsai PJ, Liu KY, Wang SE, Shyr YM, Su CH and Chen TH. Open Suture Repair and Open Onlay Technique for Incisional Hernia in Elderly Patients with Multiple Comorbidities. International Journal of Applied Science and Technology,2011,1(3): 34-40

[14] Machairas, A., Misiakos, E.P., Liakakos, T., \& Karatzas, G. Incisional hernioplasty with extraperitoneal onlay polyester mesh. American Surgeon, 2004,70(8), 726-729. 
[15] Goda El-Santawy HM, El-Sisy AA, El-Gammal AS, El-Kased AF, Sultan HM. Evaluation of retromuscular mesh repair technique for treatment of ventral incisional hernia. Menoufia Med J 2014;27:226-9.

[16] Leithy M, Loulah M, Greida HA, Baker FA, Hayes AM. Sublay hernioplasty versus onlay hernioplasty in incisional hernia in diabetic patients. Menoufia Med J 2014;27:353-8.

[17] Burger JWA, Luijendijk RW, Hop WCJ, Halm JA, Verdaasdonk EGG, Jeekel J. Long-term follow-up of a randomized controlled trial of suture versus mesh repair of incisional hernia. Annals of Surgery 2004;240:578-85

[18] Burger JWA, Lange JF, Halm JA, Kleinrensink GJ, Jeekel J. Incisional hernia: early complication of abdominal surgery. World Journal of Surgery 2005;29(12):1608-13.

[19] Korenkov M, Sauerland S, Arndt M, Bograd L, Neugebauer EAM, Troidl H. Randomized clinical trial of suture repair, polypropylene mesh or autodermal hernioplasty for incisional hernia. British Journal of Surgery 2002;89:50-6.

[20] den Hartog D, Dur AH, Tuinebreijer WE, Kreis RW. Open surgical procedures for incisional hernias. Cochrane Database Syst Rev 2008, Jul 16;(3):CD006438.

[21] White TJ, Santos MC, Thompson JS. Factors affecting wound complications in repair of ventral hernias. Am Surg 1998;64:276-80.

[22] Stoppa RE. The treatment of complicated groin and incisional hernias. World J Surg 1989;13:545-54.

[23] Dubay DA, Wang X, Kuhn MA, Robson MC, Franz MG. The prevention of incisional hernia formation using a delayedrelease polymer of basic fibroblast growth factor. Ann Surg 2004; $240: 179-186$.
[24] Saeed N, Iqbal SA, Shaikh BA, Baqai F. Comparison between onlay and sublay methods of mesh repair of incisional hernia. J Post Med Inst 2014; 28(4): 400-3.

[25] Milad NM, Said SM, Samir M. Comparison between onlay and retromuscular drainless mesh repair for para-umbilical hernia with divarication of recti. Kasr El Aini J Surg 2009;10:11-6.

[26] Nau P, Clark CJ, Fisher M, Walker G, Needleman BJ, Ellison EC, Muscarella P. Modified rives-stoppa repair for abdominal incisional hernias. Health. 2010, 2: 162-169

[27] Schumpelick, V., Junge, K., Rosch, R., Klinge, U. and Stumpf, M. (2002) [Retromuscular mesh repair for ventral incision hernia in Germany]. Chirurg, 73, 888-894.

[28] Welty, G., Klinge, U., Klosterhalfen, B., Kasperk, R. and Schumpelick, V. (2001) Functional impairment and complaints following incisional hernia repair with different polypropylene meshes. Hernia, 5, 142-147.

[29] Timmermans L, de Goede B, van Dijk SM, Kleinrensink GJ, Jeekel J, Lange JF. Meta-analysis of sublay versus onlay mesh repair in incisional hernia surgery. Am J Surg. 2014 Jun;207(6):980-8.

[30] Venclauskas L, Maleckas A, Kiudelis M. One-year follow-up after incisional hernia treatment: results of a prospective randomized study. Hernia 2010;14:575-82.

[31] Kumar V, Rodrigues G, Ravi C, et al. A comparative analysis on various techniques of incisional hernia repairdexperience from a tertiary care teaching hospital in South India. Indian J Surg 2012;75:1-3 